\title{
PRESENTACIÓN: LOS AÑOS DEL MENSAJE
}

\author{
Eloi GRASSET
}

Harvard University

\section{Introducción: Cincuenta años del Mensaje del Tetrarca, de Pere Gimferrer}

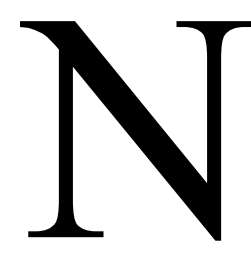

o queda ya ninguna duda sobre el hecho de que la aparición de Arde el Mar de Pere Gimferrer en 1966 supuso una ruptura respecto a los modelos que imperaban por aquellos tiempos en la poesía española. Todavía hoy, casi cincuenta años después de la fecha de su publicación, nos acercamos a él considerándolo como el libro fundacional de una estética que tuvo diferentes derivas, pero también nos acercamos a él para observar el arranque de una serie de temáticas que encontraremos en libros posteriores del autor. Estamos hablando, por ejemplo, del problema de la identidad literaria como creación deliberada, y del uso del espacio literario como el espacio óptimo para reflexionar sobre la literatura y el arte como instrumentos multiplicadores del mundo y, por lo tanto, de las diferentes identidades del que vive y escribe. Por todas estas razones Arde el mar es el inicio de algo, sin duda. La idea inicial de este dossier va en sentido contrario e intenta centrarse en el impulso inicial que entiende Arde el mar como la culminación de un proceso que se inicia algunos años antes -pocos años antes-, cuando Gimferrer escribe un par de libros, Malienus (1962) que en ese momento queda inédito y que solo será publicado parcialmente años más tarde, y Mensaje del Tetrarca (1963). Según cuenta el mismo autor, la elección de Mensaje del Tetrarca como primer libro publicado fue completamente accidental y tiene que ver con la decisión del editor, pero no por eso nos deja de hablar del primer paso en la construcción de una voz, de un impulso inicial mediante el cual el escritor resuelve una voz que se ha ido fraguando durante su primera etapa de formación. El mismo Gimferrer comentará algunos años después: "Hoy, en la distancia y en la perspectiva, quizá todo

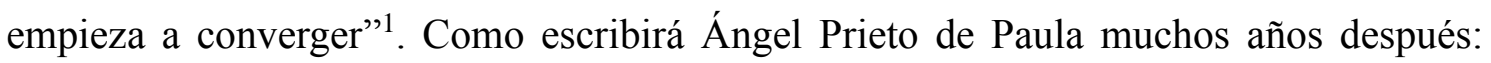
“todo él está poseído por una entonación hímnica, con fórmulas sintácticas cuyo sabor arcaizante se diría procedente de fuentes épicas [...] su plétora incendiaria, visible en el contraste entre un mundo prosaico y obsceno, por un lado, y la expresión de un yo

\footnotetext{
${ }^{1}$ P. Gimferrer, Poemas 1962-1969, Madrid, Visor, 1988, p. 25.
} 
elemental y con ansias de elevación, por otro. [...] Destaca por el acarreo de elementos muy variados, y por su verbalismo calcinador. Y todo ello orientado a expresar la insuficiencia de la existencia y la plenitud de la palabra"2.

Ya desde muy joven, con tan solo once o doce años, Gimferrer descarta la influencia de los modelos instalados en el imaginario de la poesía española del momento ${ }^{3}$ y activa un conjunto de influencias artísticas alejadas de su contexto más inmediato.

Mi desinterés por la poesía imperante entonces en España era completo, así como mi falta de respeto por las escalas de valor establecidas: a mí me gustaba la poesía modernista, la novela erótica de 1900, los folletines, etc. Mis poetas preferidos eran en España los de 27, a quienes debo mucho, y fuera de ella, además de Perse, Eliot y sobre todo Pound. En prosa Faulkner, Proust y Henry James. Siempre me sentí deudor del surrealismo. ${ }^{4}$

Sin duda, existen diferentes modelos poéticos durante la posguerra española, pero, como ya auguraba Gil de Biedma en su célebre artículo "Carta de España (o todo era Nochevieja en nuestra literatura al comenzar 1965)" "5 la primera voluntad de los jóvenes poetas que empezaban a escribir a principios de los sesenta era acabar con la hipertrofia de los modelos realistas. Como el mismo Gimferrer comenta, el significativo proceso estético que tiene lugar entre los años de posguerra y los setenta es "la pérdida de la tradición contemporánea y la lenta lucha por recobrarla"6. En este proceso de recuperación, en el que intervienen autores como José Ángel Valente, Ángel González, Claudio Rodríguez, José Manuel Caballero Bonald, Gil de Biedma, Gimferrer jugará un papel decisivo.

Además de este intento de incluirse en una tradición contemporánea recobrada, o quizás precisamente por esto, es también durante estos años que Gimferrer se interesa por otras tradiciones artísticas distanciadas de la literatura que resultarán tan importantes en la construcción de su poética. Es durante estos años que Gimferrer descubre el jazz y empieza a definir sus gustos cinematográficos: "Descubrí el jazz y empezaron a perfilarse mis gustos cinematográficos. Se inició mi pasión por el cine, y casi exclusivamente por el cine americano $[\ldots]^{\prime \prime 7}$. Y es también durante estos años que el autor empieza a colaborar en distintas publicaciones como Tarrasa Información, El Ciervo, Papeles de Son Armadans, Film Ideal o Ínsula. La crítica literaria y cinematográfica se convierte en una manera que encuentra el autor de posicionarse respecto al mundo literario, convocando autores provenientes de la tradición hispanoamericana o escribiendo sobre autores extranjeros desconocidos por el público español. La especial dedicación del autor a la

\footnotetext{
${ }^{2}$ A. L. Prieto de Paula, Musa del 68, Madrid, Hiperión, 1996, p. 46.

${ }^{3}$ P. Gimferrer, "Itinerari d'un escriptor”, en Valències, València, Edicions 3i4, 1993, p. 24.

${ }^{4}$ P. Gimferrer, "Poética", en J. M. Castellet, Nueve Novísimos (1970), Barcelona, Península, 2001, p. 152.

5 J. Gil de Biedma, "Carta de España (o todo era Nochevieja en nuestra literatura al comenzar 1965)", en

El pie de la letra, Barcelona, Crítica, 1994 [1980], p. 187.

${ }^{6}$ P. Gimferrer, "El pensamiento literario (1939-1976)", en J. M. Castellet (ed.), La cultura española bajo el franquismo, Barcelona, Ediciones de Bolsillo, 1977, p. 108.

${ }^{7}$ P. Gimferrer, "Poética", en J. M. Castellet, Nueve Novísimos (1970), op. cit., p. 152.
} 


\section{Eloi Grasset}

crítica forma parte del proyecto literario del escritor que conlleva la fragua de un firme criterio estético. A algunos de los autores sobre los que escribe les dedicará, años después, amplios y detallados estudios como puede ser el caso de Octavio Paz o J. V. Foix. Es también en estos años que Gimferrer establece contacto con autores como Brossa, Vicente Aleixandre, J. V. Foix o Jaime Gil de Biedma. Como comenta el mismo poeta, el arte, la literatura es el centro sobre el que se organiza toda su vida. Todo cambio que tendrá lugar durante estos años está ligado de alguna manera al peso que el arte tiene en su vida: "Mi timidez y mi desfase del mundo exterior contribuyeron a encerrarme de tal modo en la esfera del arte que puedo decir que hasta mis veinte años no vivía para otra cosa"8. De esta manera, el acercamiento a la literatura desde la lectura resultará clave para entender de qué manera se resuelve su acceso a la escritura: "El paper, respecte a mi mateix, de qualsevol poema meu, és equivalent al paper que, per a mi, té el llegir Rimbaud o Lautréamont (i a l'inrevés)"9. Evidentemente, el peso de la tradición es importante para entender que el itinerario del escritor va ligado al itinerario del lector. Aun así, según el mismo Gimferrer comenta, se producen un par de hechos que resultan decisivos para entender su paso definitivo a la escritura ${ }^{10}$ : por un lado, Gimferrer descubre la literatura de Rubén Darío y, por otra parte, en un momento dado escribe algo que él mismo considera "literatura adulta". Este es el último y decisivo paso en la toma de consciencia de la configuración de una voz propia.

De la recepción de sus primeros textos llama la atención la delicada consideración que le dispensó el poeta Vicente Aleixandre a quien Gimferrer había mandado los poemas de su primer libro, Malienus ${ }^{11}$ :

En último término, o en primero, es una disconformidad, una ruptura, y yo estimo que un poema escrito así por un joven de diecisiete años, y ahora, en estos años, no significa retraso (como pensaba usted lo podrían estimar), sino una forma de adelanto: es aparte de otras cosas, una protesta contra una escritura ya gastada, sin capacidad de reacción.

Además de la carta de Vicente Aleixandre, que hará pública el mismo Gimferrer, y debido a la poca difusión que tuvo Mensaje del Tetrarca, no quedó constancia de la recepción crítica del libro. Referido a Mensaje del Tetrarca encontramos un único artículo de Álvaro Cunqueiro, publicado en El faro de Vigo en el que el escritor nos habla de la excepcionalidad del volumen: "De todos los libros de poesía leídos en estos últimos tiempos, Mensaje del Tetrarca, es el que más me ha sorprendido y despertado"12.

A nuestro entender, y como decíamos al empezar, con la publicación de Mensaje del Tetrarca, libro que no se reeditará hasta veintidós años después, se pone en marcha

\footnotetext{
${ }^{8}$ Ibid., p. 151.

${ }^{9}$ P. Gimferrer, L'agent provocador, Barcelona, Edicions 62, 1998, p. 25.

${ }^{10}$ P. Gimferrer, Valències, op. cit., pp. 26-29.

11 "Carta de Vicente Aleixandre. 15-7-1965", en P. Gimferrer, Poemas (1962-1969), Visor, Madrid, 2000.

${ }^{12}$ L. A. (Álvaro Cunqueiro), "Comentario a Mensaje del Tetrarca", El Faro de Vigo, 1964 [publicado en Anthropos, 140, (I/1993), p. 71].
} 
una voz extremadamente singular en el panorama literario español y da inicio a un conjunto de preocupaciones -temáticas, críticas, estilísticas- que iremos encontrando en la obra posterior del autor. Este dossier quiere dar cuenta de todo lo que pone en marcha esta voz para proyectarse en todo lo que tendrá que venir posteriormente, y desde esta idea se ha fraguado.

El dossier se ha dividido en tres partes. En la primera parte, que lleva por título "Los años del mensaje", hemos recogido algunos artículos que se centran en el análisis de algunos aspectos concretos de la obra de Gimferrer durante esos años. Marie-Claire Zimmermann en "La voz poemática y el verso en Mensaje del Tetrarca" se aproxima a la configuración de la voz de Pere Gimferrer prestando especial atención a algunos aspectos estructurales y estilísticos de los poemas, para pasar a reflexionar sobre las distintas identidades que toma el locutor en el poemario. José Francisco Ruiz Casanova en su artículo "Los niños perdidos de Castellet" se pregunta por el lugar que ocupa la generación de los novísimos en la historia de la literatura española y qué rastro queda de ella; José Luis Rey Cano, en "Intertextualidad en la poesía primera de Gimferrer”, analiza las referencias intertextuales en los primeros poemarios del autor, centrándose en la identificación de algunas referencias que resultan importantes en esos años. Para acabar esta primera parte, Túa Blesa en su artículo: "«Invocación en Ginebra» de Pedro Gimferrer: una lectura (con una carta de Gimferrer a José Angel Valente)" escribe sobre uno de los poemas clave de Gimferrer que aparece en Arde el mar y hace una lectura que sitúa el poema muy lejos de la falta de compromiso político que históricamente se ha asociado a la escuela novísima.

La segunda sección del dossier está dedicada al itinerario del escritor y se ha organizado a partir de las distintas resonancias que su obra primeriza proyecta sobre el resto de su producción. El primer texto de esta sección es de Juan José Lanz y lleva por título "Caligrafía del Fuego y caligrafía de oscuridad"; nos habla de las distintas voces que se van configurando en el itinerario del escritor, para centrarse en el análisis del poemario Rapsodia que, según el autor, supone un ejercicio de recapitulación de toda la obra precedente del poeta. Siguiendo con la última etapa de la producción del autor, Luis Miguel García Jambrina en su artículo: "Un nuevo ciclo de poesía en castellano en la trayectoria de Pere Gimferrer" escribe sobre la última poesía castellana de Gimferrer, desde Amor en Vilo hasta Alma Venus, y Stefano Torresi con "Una nueva historia de amor: Interludio azul" estudia las referencias cinematográficas que aparecen en el mismo último ciclo castellano, particularmente en Interudio Azul. La última sección del dossier, "Hibridaciones y lecturas" se centra en el espacio crítico que desarrolla Gimferrer desde sus primeros años. Enric Bou, en su artículo "El caliu i la cendra. Pere Gimferrer y las afinidades literarias" nos habla de algunos nuevos espacios generados en el cruce entre lectura y escritura en la obra del poeta. Eduard Cairol en "El agente provocador: Pere 


\section{Eloi Grasset}

Gimferrer y la literatura artística" escribe sobre el peso de la crítica de las artes plásticas en la obra del poeta y las conexiones que estas generan en su espacio literario, mientras que Lídia Carol nos habla de la relación iniciática que Gimferrer mantiene con el cine en "Pere Gimferrer: Cinéfilo, Crítico, Teórico y Amateur de Cine". Siguiendo con el trabajo crítico de Gimferrer, Manuel Rico escribe sobre su crítica literaria y el particular enfoque crítico de Gimferrer en su libro Radicalidades. Esta sección termina con un texto de Anna Esteve sobre el Dietari y la hibridación genérica a partir del trabajo de Gimferrer sobre el género autobiográfico.

Para terminar el dossier hemos querido dar voz al recuerdo de una figura representativa de los años del mensaje, Francisco Ferrer Lerín. Gimferrer y Ferrer Lerín se conocieron en la universidad en el curso 62-63, y según cuenta Gimferrer, "fue la persona con quien sostuve más abundantes y extensas conversaciones sobre arte y literatura. Quiero decir, que descubrimos juntos muchas cosas. Me parece que éramos los únicos estudiantes que en la Universidad teníamos en aquellos años algún interés por el surrealismo y el arte de vanguardia en general"13. Quede, pues, la semblanza que Ferrer Lerín hace de Gimferrer como testimonio de esos años en los que empezó a fraguarse una poética que todavía está en marcha y de la que todavía esperamos mucho.

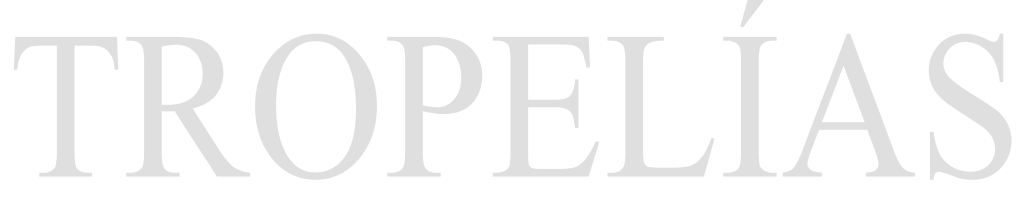

${ }^{13}$ P. Gimferrer, "Prólogo", en F. Ferrer Lerín, La hora oval, Barcelona, Barral, 1971. 